\title{
RESEARCH ON THE GROWTH MECHANISM OF THE CRUISE INDUSTRY
}

\author{
Ling Sun \\ Shanghai Maritime University, P.R.China \\ Huangming Xie \\ Shanghai Maritime University, P.R.China \\ Hanwen Zhang \\ Shanghai Maritime University, P.R.China \\ Wei Liu \\ Shanghai Maritime University, P.R.China
}

\begin{abstract}
The growth of the cruise industry refers to a process in which the cruise industry experiences its life cycle. The growth mechanism of the cruise industry can be divided into exogenous dynamic mechanism and the endogenous dynamic mechanism. In this paper, we build a simple cruise industry growth momentum mechanism model and put the cruise industry growth in a comprehensive environment. Followed by analysis of exogenous dynamic mechanism and the endogenous dynamic mechanism, we can obtain the best path of cruise industry growth. And the growth path of the cruise industry can be divided into the initial period, rising period, mature period and ideal period. Meanwhile, different development suggestions are put forward for each period of the cruise industry. It is hoped that the research of this paper can provide reference for the development of cruise industry.
\end{abstract}

Keywords: cruise industry; growth mechanism; growth path; ecosphere

JEL code: L920

\section{Introduction}

The cruise industry mainly consists of 3 industries, which are transportation, sightseeing and leisure, tourism (Peter and John, 2000). The development of the cruise industry includes many categories, like the design and construction of cruise ships, cruise port construction, cruise service, tourism transportation, cruise supplies, cruise financial insurance, etc (Wang et al. 2014).

The global cruise industry is growing at an average rate of $8-9 \%$ every year. During the last 
30 years, the growth rate of cruise passengers reached an alarming rate of $1460 \%$. Taking North American cruise industry as an example, the number of passengers have been extended to about 10 million from the initial 0.5 million. The report also analyzes the growth rate of various tourism industries. The average annual growth rate of the international tourism industry is $4 \%$, and the cruise industry has the fastest growth rate in all tourism industries (Iwata and Matsuda, 2003).The growth mechanism of the cruise industry refers to the cruise industry experienced a process of its life cycle. External performance is the process that cruise industry from scratch, from weak to strong; internal performance includes industrial organization, industrial scale and industrial technology. The scope of industrial organization is quite small. It only refers to the collection of companies involved in cruise services. The industrial organization refers to the market relations and the organization form of the relevant enterprises in the cruise industry. This concept includes two meanings.

The former refers to the monopoly and competition of the same type of enterprises in the cruise industry which reflects the differences in market dominance, market position and market effect of different firms in the cruise industry. The latter refers to the organizational form of the cruise companies interconnected. These different forms of industrial organization depend on the different forms of monopoly and competition among enterprises. The upper and lower press, competition and cooperation between enterprises will have an impact on the industrial organization.

Adam Smith proposed the study of industrial growth in the " An Inquiry into the Nature and Causes of the Wealth of Nations " two hundred years ago (Adam, 2007). Based on the theory of evolution, Alfred Marshall expanded to the growth of industry. He believes that industry is a tree, and industry enterprises are leaves, each leaf has its own characteristics. The industry has a long and stable growth space, like trees that can grow year after year and suffer long-term fluctuations. And the enterprise in the industry will experience growth and decline, like leaves' germination and wilt (Marshell, 1920). Michael Porter first proposed that the relationship between organizations affect the growth of the industry. In his "Diamond Model", the growth of the industry is summed up as the factors of production, the conditions of demand, the situation of supporting industries, etc (Michael, 1998). Through the analysis of comprehensive factors, Xiang (2005a) concludes that industry growth is significant influenced by market demand, policy, technological innovation and investment. Based on this, the dynamic mechanism model of industry growth is constructed. Lu (2002) proposed that the growth mechanism of the industry is mainly made up of the promotion of supply, the pull of demand, the promotion of technology and the traction of division of labor. Chen (2008) analyzed the direct and indirect dynamic mechanism of industry growth and thought that the direct power mechanism included the technology of industry, the demand of market and the substitution of product. If the product cannot be replaced, then the industry's life cycle, its technology and products will experience the same life cycle. In the indirect dynamic mechanism, the fluctuation of market price can mediate the indirect power spontaneously. On this basis, a growth dynamic model based on Logistic is proposed. Xiang(2007b) analyze the characteristics of the four life cycles of industry growth and the mechanism of each stage. Based on these mechanisms, the method of identifying the phases is also proposed. 
Combining with the theoretical research on the growth of industry, we can conclude that the growth of the industry must go through four stages: initial period, growth period, maturity period and recession period. In this paper, the growth of the industry only consider the initial, growth and maturity period. This paper has the same research theme with Michael Porter proposal, which the relationship between the growth of the industry can affect the growth of the industry

\section{Dynamic mechanism of industrial growth}

The cruise industry as an evolutionary system, there must be its dynamic mechanism. In order to reveal these mechanisms, the method of system theory can be adopted, especially Self-organizing method. In fact, the growth of the cruise industry is also the process of self-organization evolution. There are also internal units in the industry--competition and cooperation among enterprises.

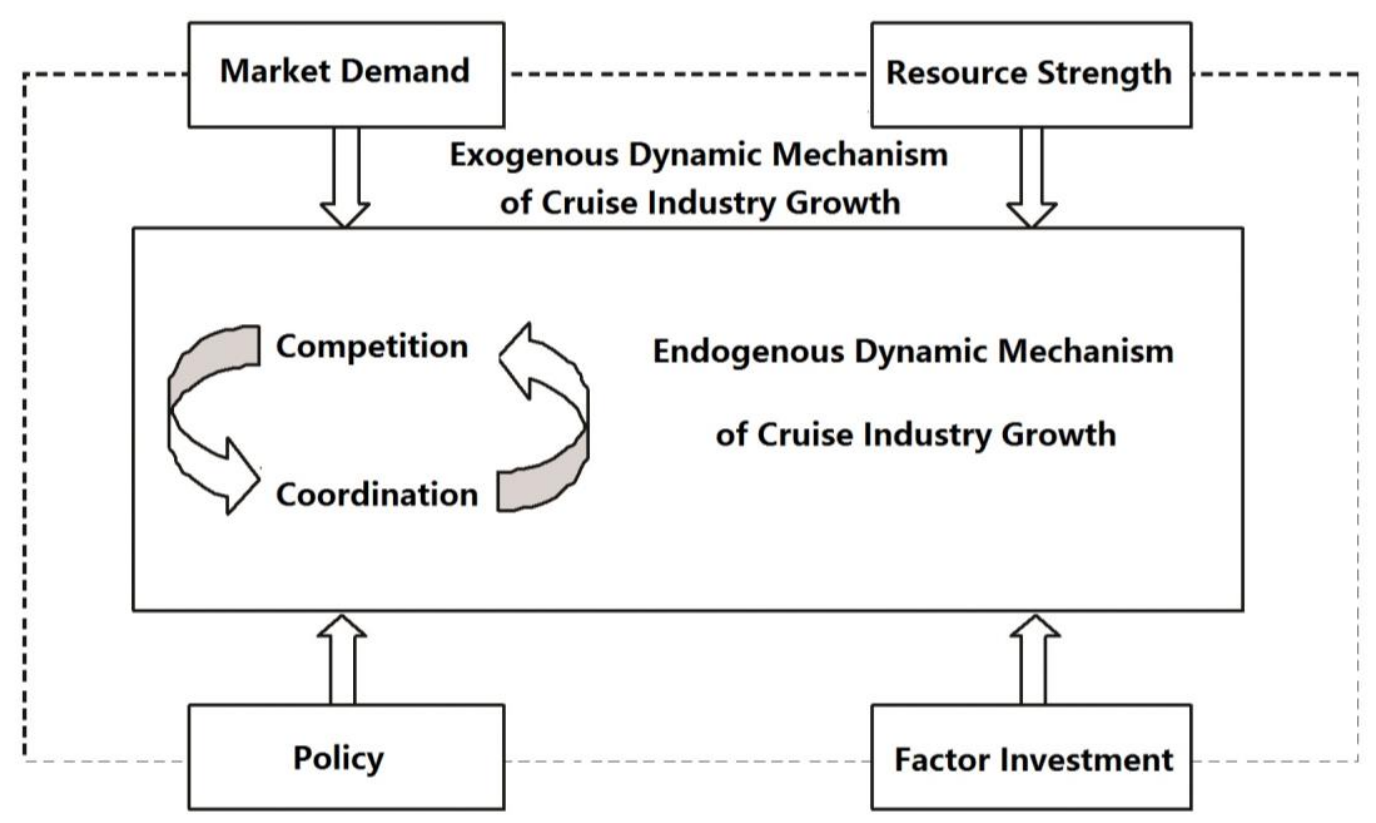

Figure 1. Growth dynamics method of cruise industry

In Figure 1, it can be concluded that competitive advantage of enterprises comes from internal resources and capabilities, and depends on the establishment of network relationships with external enterprises and institutions to obtain strategic resources as well. The external dynamic mechanism of cruise industry is reflected in four aspects, which are market demand, resource advantage, policy and factor investment. According to the economic law of the development of the international cruise, when GDP per head reaches $\$ 10000$, the development of the cruise industry has the proper conditions of market demand. The resource advantage refers to the cruise home port berthing port environment, and the advantages of tourism resources, various factors and policy support. The internal dynamic mechanism of industrial growth is the competition and cooperation of enterprises. When the network 
relationship characteristic reaches the optimum state--Inter firm trust, relationship persistence, relationship strength and other characteristics, competition and cooperation of all parties can maximize economic benefits and make cruise industry thriving. In this paper, a simple model of growth dynamics of cruise industry in an integrated environment is built. The interaction between exogenous and endogenous mechanisms, dynamic mechanism between the elements are interrelated and interact, under certain conditions, exogenous dynamics can be transformed into endogenous power. It is the dynamic mechanism of this kind of system that provides a comprehensive driving force for the growth of industry promote the growth and evolution of the cruise industry.

\section{External dynamic mechanism of cruise industry}

\subsection{The guiding role of market demand for cruise industry growth}

Cruise market demand refers to the tourist motivation the need or desire. From a microeconomic perspective, the demand for tourism can be defined as the willingness of a tourist to cruise at a given time (such as a holiday) and a given price. If the tourist has the demand or the desire to the cruise travel, but lacks the economic ability, it cannot be regarded as demand. In this paper, the demand should be effective. That means it is actual consumption. Because of the difference of tourism economic status and income, the demand is also showing diversity, therefore, cruise has more types of space class, different space to meet the different needs of tourists.

In the specific economic and social conditions, especially in the era of peace, tourism is the most dynamic industry in the third industries. The Industrial structure upgrading driven by the escalating mainstream demand, construct the cruise market profits. Under the market mechanism, more and more cruise for berthing, promote large-scale cruise ships, ship facilities and other means of production are constantly upgrading. And it creates the rise of new industries and cruise service supply chain rises. Progressively, the development of the cruise industry can be promoted.

\subsection{The supporting effect of resource superiority on cruise industry growth}

The development of modern cruise has been more than 50 years since 1960, entering the mature period. But there are still many coastal cities in the construction of the cruise industry, especially in Asia. The cruise industry resources advantages, is the basis of the growth of the cruise industry, cruise tourism has some irreplaceable advantages in resources, such as important historical sites, shore culture, international conferences, exhibitions, natural resources, port climate. Conversely, for example, port is a port of frozen, that a year of departure times will be restricted. For example, during the World Expo Shanghai reception international cruise ships have more obvious change. The success of the expo 2010 led to cruise ships call increased dramatically. But in 2011, there is an obvious decline, which means World Expo has a great effect on cruise ship berthing. With the continuous investment of China's cruise industry, in 2012 and beyond, cruise tourism ushered in the era of great 
development. Therefore, the resource advantage will have a huge impact on the growth of the cruise industry.

\subsection{The Role of Factor Investment in the Growth of Cruise Industry}

The factor of the cruise industry investment can determines the growth of the cruise industry, as well as the level of growth, which include new cruise ship, the ship upgrading of leisure entertainment, berthing hardware facilities, port shore tourism project investment, good language ability of high quality employees, etc.

The role of factor investment in the growth of the cruise industry is manifested in both horizontal and vertical aspects. Horizontally, it expands the scale of cruise industry, improves the new cruise orders continuously and increase passenger capacity year by year. Judging by the number of new members of the North American Cruise Association, in 2015-2020 years, 33 new cruise ships will be built. Meanwhile, the total cost accounts for $\$ 25$ billion 650 million. Compared with the increasing number of passenger and cruise fleet capacity, the accident rate is reduced year by year. It shows the investment in security elements plays a significant effect. Vertically, by increasing R\&D costs, to promote the technical progress of the cruise industry, such as VR technology on board entertainment facilities, convenient and efficient shore transportation, solar cruise applications, etc. In the early stage of the cruise industry, factor investment has given birth to a new industry, which is the role of venture capital. In the growth stage, the factor investment helps create the favourable condition for the cruise industry economies of scale. In the mature period, factor investment promotes the upgrading of the cruise industry technology. In recent years, more and more investment in technology has focused on the construction of recreational facilities on board. In the recession of the cruise industry, factor investment will be the restructuring of the cruise industry to create vitality.

Insufficient or excessive investment factors will adversely affect the cruise industry. The lack of factor investment make it difficult to promote the growth of the cruise industry, especially cruise companies and port enterprises are heavy assets of enterprises, the construction of the whole industry chain infrastructure needs a certain scale, due to the port berthing facilities, there is a minimum investment scale. On the other hand, excessive investment caused by excessive competition in the cruise industry, for example, the same city or two adjacent cities, built many cruise ports, it will bring excessive competition, and the cruise port construction cycle is long and costly, excessive competition will destroy the cruise industry low profit line, and to throw the early investment in to wind, and delay the growth of the industry.

\subsection{The support for cruise industry growth by the top-level design}

The top-level design of cruise industry and some other excellent and convenient policies constitute the macro environment for the growth of the cruise industry. The introduction of policies can support or inhibit the growth of one or some industries. Cruise tourism belongs to the international tourism, so visa-free policy implementation can be a very good support for 
the growth of the cruise industry. And the cumbersome visa procedures inhibit the growth of the cruise industry to some extent. In addition, a lot of goods on the cruise belong to the global procurement. Access facilitation is also an important means to support the growth of the cruise industry.

Because of the cruise industry chain link, policy involves many departments. Cruise industry requires a great deal of overall coordination with the international practice. The related organization consists of the NDRC, port, customs, inspection, quarantine, maritime and other departments of the coordination and communication between government departments and relevant enterprise can be set.

Strengthen the government for cruise-related enterprises and institutions of the preferential efforts, such as voyage subsidies, ship goods export tax rebates and local business preferential policies to encourage the cruise industry healthy and orderly development, and part of the cruise business enterprises and institutions issued the corresponding entry and exit tourism qualification to achieve healthy market competition.

\section{Internal dynamic mechanism of cruise industry}

\subsection{Competition mechanism}

Competition is an important mechanism to promote the evolution of industrial organization. When the enterprises of the same type and level in order to gain greater benefits, competitive relationship forms. For example, there is a competitive relationship between different cruise companies and travel agencies in the same region. In the original high profit environment, the continuous influx of new enterprises to participate in the supply side is greater than the demand side, through continuous competition, the price gradually reduced, the quality of service is increasing, the company's profits continue to decline.

With the deepening of the competition, the enterprises with the ability to open up the market, a high level of management, strong product development ability will become the industry leader. On the other hand, uncompetitive enterprises will be eliminated. And the concentration increases, resources will be optimally configured, industry tends to be strong and sturdy. In this process, the integration of the cruise industry is very important. In the process of the evolution of industrial organization, competition is a big trend, but when the enterprise is faced with the common interests, the cooperation relationship replaces the competition. This is also a reflection of the growth of the industry.

\subsection{Cooperation mechanism}

In the cruise industry, any enterprise is not isolated to compete. In the process of competition, while maintaining cooperation between enterprises. This collaboration is first manifested in the division of labour. For example, port companies play an integrator with cruise service. And travel agents act as integrators of tourism services. Although there are competing 
relationships between the same types of business, they maintain a cooperative relationship with downstream service providers.

In the cruise industry, cruise service supply chain brings together a number of enterprises, which forms an interdependent and mutually reinforcing relationship. This kind of cooperative relationship is based on the interests of the core driving mechanism, resource based mechanism to promote the brand, market, information and subsidies as a means of mechanism. For the sake of interests, enterprises will be based on their own resource characteristics through market sharing and information exchange to reduce costs, while the subsidy mechanism to achieve cost sharing of the cooperation model to improve the common income.

In the aspect of resource sharing mechanism, the spatial part of the tourism resources across borders, cruise tourism because of its particularity, its tourism resources space is constantly changing, with the port city hinterland tourism resources geographical characteristics, construct the unique tourism resources. The development of tourism cooperation across space can ensure the integrity of tourism resources, promote the sustainable development of tourism, and ensure the construction of cruise tourism ecological circle.

In the information interaction mechanism, implementation of cruise service providers collaborative development need to view various elements and levels of resources as a consortium, rely on a variety of advantages to do collaborative development. To achieve a reasonable allocation of resources in the development of cruise tourism products, it is necessary to link the cruise industry advantage to fully blend in cruise tourism ecosystem, achieve depth transformation and combination. In order to promote the exchange of information between various cruise tourism products in circulation, flexible market development as well as the local government's security policy should be made full use of.

In the aspect of benefit sharing mechanism, we can get the maximum benefit by sharing resources, information exchange, sharing market and mutual subsidy. On the basis of sufficient information exchange, we will develop the characteristic tourism products and routes which belong to the cruise service supply chain cooperation, excavate the potential consumption of the tourists, promote the development of the marginal economy and increase the income of the tourists.

In the aspect of market sharing mechanism, the development of cruise tourism industry has obvious seasonal characteristics. Northern Hemisphere 3 to 10 months each year is cruise season. Northern Hemisphere 3 10 months for the cruise season (the southern hemisphere is the opposite), during this time a large number of tourists are transported. Low season cruise tourism is idle, resulting in a huge waste of tourism resources. Through the sharing of tourism resources with the hinterland of the port, we can balance the great difference between the light seasons.

In terms of brand sharing mechanism, cruise tourism brand image planning is based on the 
characteristics of cruise tourism market demand for product development by shaping the image of a relevant and distinctive, to ensure that the cruise tourism products smoothly into the market.

In terms of cost subsidy mechanism, cruise tourism industry development lies in the cost of tourism planning, development, marketing, shipbuilding, port facilities construction, the tourism development and marketing planning alone are repeated investment cost, and the coordination mechanism in collaborative marketing, publicity, sharing time, can share the cost and reduce the cost. The tourist route design and product experience due to the time limit cannot meet the needs of tourists, in order to dig the biggest potential consumption of tourists, and tourists get the highest satisfaction, which requires enterprises must give cruise tourists enough time, and sent a large number of tourists to the port city. Therefore, when the cruise berthing at the cost of proportion subsidy tourist attractions, the port enterprise also can give a certain discount, a certain amount of relief port disbursement, to ensure the win-win of the liner service supply chain.

\section{Growth path of cruise industry}

The cruise industry members have various types of enterprises and services range is wide, the specific structure as shown in Figure 2. In order to simplify the growth path of the cruise industry, the cruise industry members divided into three classes, cruise company in the supply chain service is the core position, the travel agency and the port at the same level, tied in the middle position of service supply chain, the travel agency, insurance companies, catering services, tourist attractions, road traffic service providers are at the same level, which belongs to the tourism service providers. Port transport services, auxiliary services, waste disposal system provider, ship supply enterprises are at the same level, which belongs to the function of service provider, service provider and service provider of tourism function in the downstream supply chain services listed. 


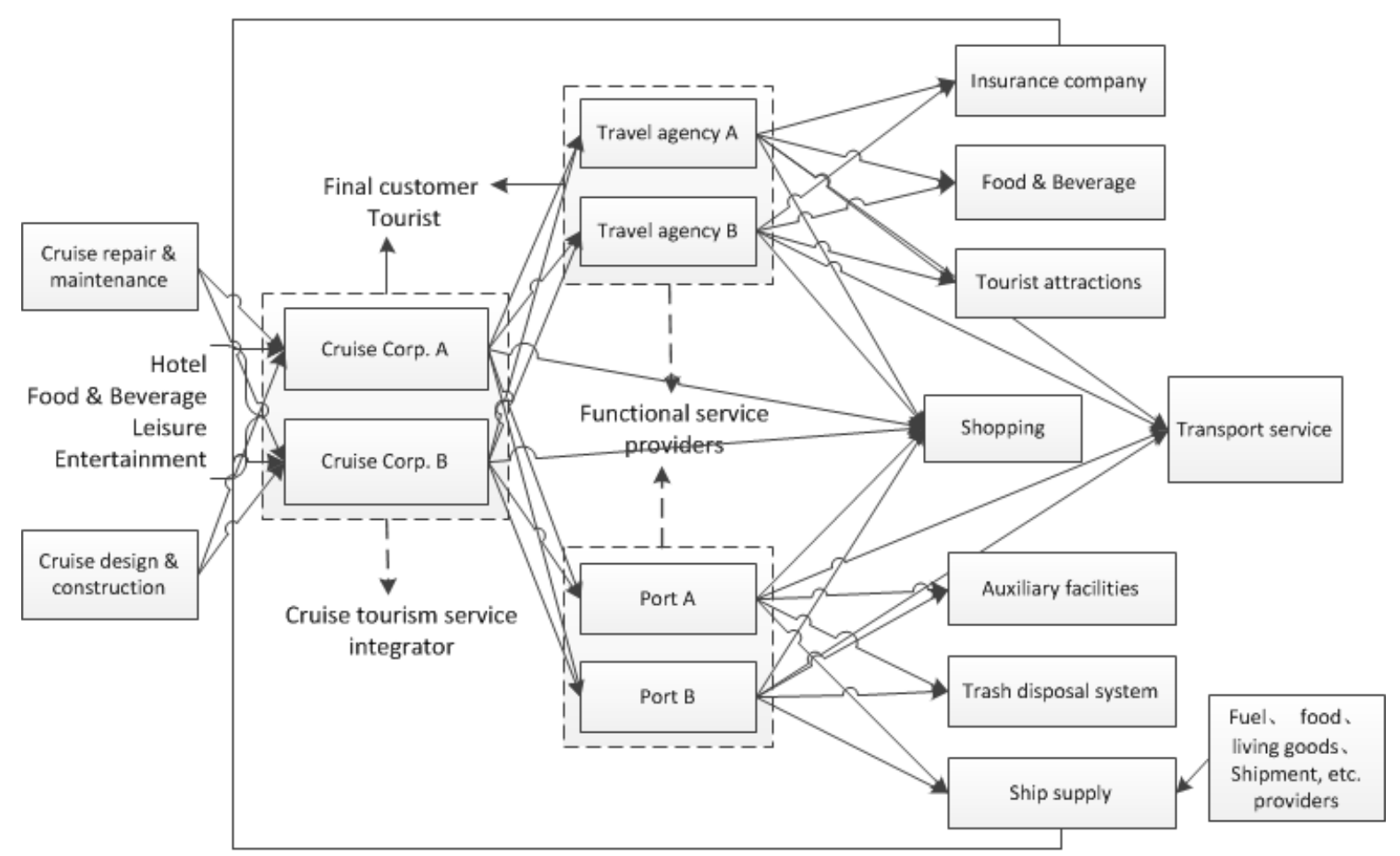

Figure 2. The structure of cruise industry

As the port and most of the functional service providers, not only the cruise industry on the business relationship, more in the merchant also carried out business contacts. Similarly, between travel agencies and most travel service providers, not only in the cruise industry, but also in other tourism between the close. Therefore, this paper argues that port enterprises and functional service providers, travel agencies and travel service providers, the cooperation between the two will be the easiest and fastest to reach. Combined with the dynamic mechanism of industrial growth model, this paper argues that this article proposed the cruise industry's fastest, most versatile and easiest way to grow as shown in Figure 3. The dotted line is expressed as a stable cooperative relationship between each other, or mutual stock, acquisition, etc., that is, in the ideal period, all enterprises have carried out cooperative relations. 


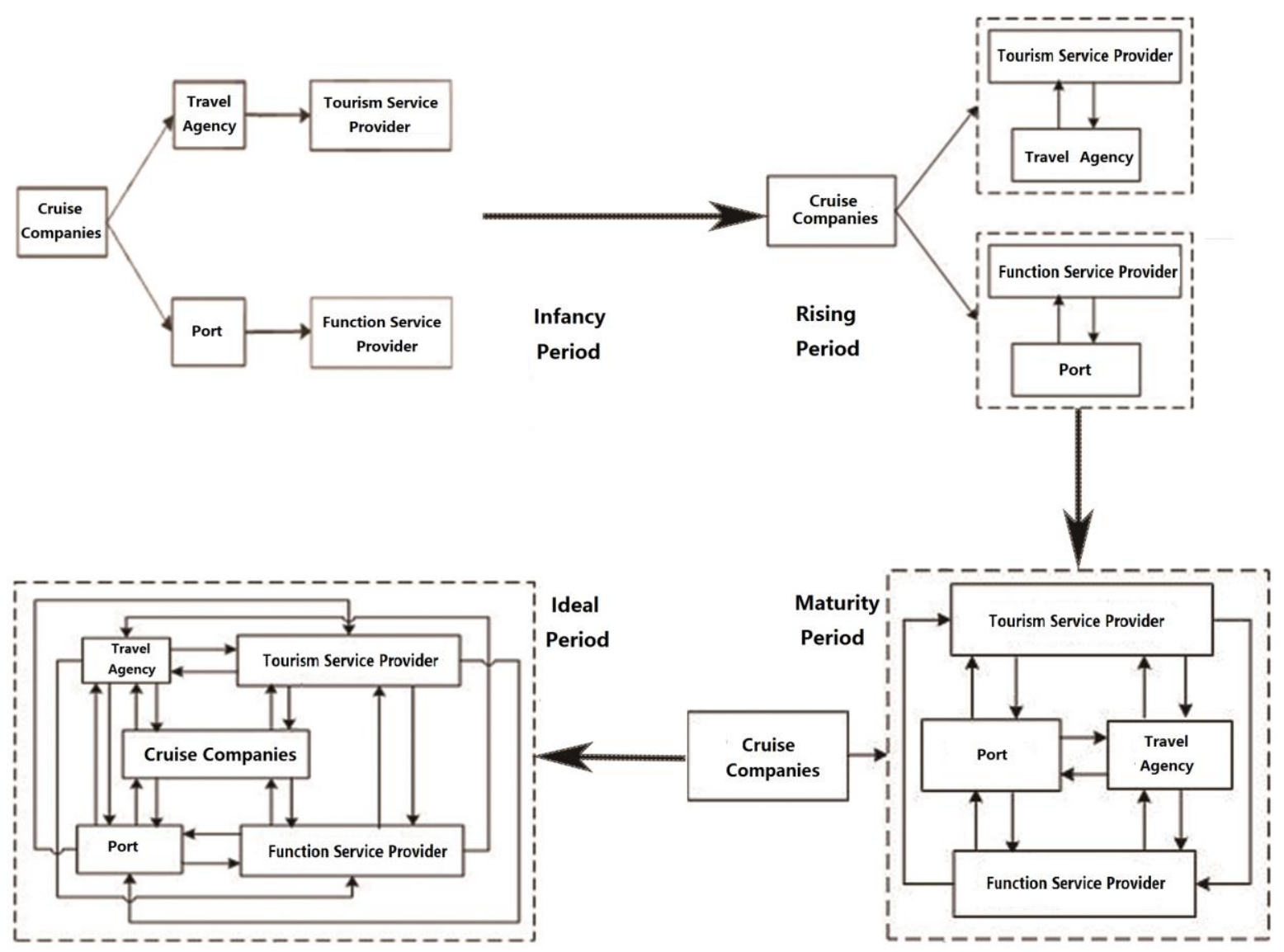

Figure 3. The path of cruise industry growth

\subsection{The initial period}

In the early stage of cruise service supply chain, market demand leads to the development. According to the economic law of the development of the international cruise, when GDP per head reached $\$ 10000$, cruise industry will meet the conditions of development, promoting the rise of the coastal city of cruise industry. International cruise's visit will bring to the economy of the local and surrounding areas a certain role.

In infancy stage, cruise company takes the position of dominance. The local port can only gain profit by cruise ship callings. There are some reasons for this phenomenon. Firstly, the local port companies lack mutual trust with each other and lose their dominance. Secondly, the policy is not perfect enough. Thus, the policy matches to the characteristic of cruise industry should be wide and sufficient and ensure the development of cruise industry.

With the improvement of cruise service, the differentiation of function service and tourism service grow larger for customers' preference. This promotes many specialized, competitive cruise service providers. With the increasing of competition and the investment in cruise service elements, cruise service supply chain will gradually improve and enterprises will embark on the road of specialization. Travel agents can be targeted for outbound travelers, 
design cruise routes and strengthen the cruise line travel promotion according to their cultural habits, consumption patterns. At the same time, they can tap the cruise of local tourism potential, develop in line with the domestic tourist culture and a specific theme cruise tourism products.

At the same time, we should vigorously promote the training of various industries in the cruise ship, in the relevant institutions of higher education institutions to set up relevant professional advanced courses, training and delivery of international vision and practical ability of senior management personnel. What's more, actively learn from the international cruise economy developed countries and introduce of foreign senior cruise management personnel. Encourage and guide the combination of higher education and regional economy, combined with regional talent strategy.

\subsection{The rising period}

Typical ports at this stage are Hong Kong, Busan and Singapore. During this period, although cruise companies, still occupy the absolute dominance, the local corporate profitability has been significantly improved.

As for policy, to further improve the relevant regulatory system and specific methods, the development of relevant service standards and business behavior should be made. The tourist projects and port services provided by the port of attachment are part of the direct contact with the consumers, which directly affects the contribution of the cruise industry to the regional economy. Local governments should formulate appropriate policies to encourage relevant enterprises in the region to develop corresponding tourism projects for different market segments, and vigorously develop the cruise derivative industry, providing personalized and diversified services to meet the needs of different consumer groups. At the same time, further refine the introduction of cruise ship free of charge, cargo clearance, shipping and other policies to support the development of cruise service supply chain.

In the factor investment, the construction of the port of the cruise ship is inseparable from the supporting business and service industries, including the ship supply industry, transportation industry, operation service industry, supporting facilities construction, recreation business environment around the port area, large commercial comprehensive project development and so on.

The development of the port of the cruise ship must pay attention to the comprehensive development of the related functions of the surrounding area. The geographical location should be taken full advantages to attract cruise passenger. Thus, the downstream supporting services will have more opportunities for intervention. The development of high value-added business, tourism, entertainment, catering and other projects, set up more integrated reception, such as cruise supply, maintenance and repair, waste disposal, these consumptions will bring a series of economic effects, and through the industry chain Extension, so that the economic benefits of the home port to maximize. 
Drawing on Hong Kong, Busan and Singapore, the development of this stage should focus on the establishment of cruise ship for the logistics centre, including storage, transportation, handling, processing, packaging, information processing, distribution and other basic functions. Cruise goods with large quantities, high value, strict time and other characteristics, the establishment of cruise ship for the logistics centre, the distribution model will be changed to centralized distribution model. Cruise goods in the centre can enjoy the bonded, customs clearance and other preferential policies to focus on warehousing, transportation, transit, etc., to attract more cruise companies in the local material procurement, and promote the development of cruise material distribution. For the cruise to provide first-class professional, integrated logistics and distribution services, driven cruise ship for the development of the market and the cruise industry to enhance the function.

\subsection{The maturity stage}

The typical port of this stage is the port of Miami. In the maturity stage, the home port economy should be paid more attention. With the upgrading of the right to speak of local enterprises, in order to gradually scale the cruise market demand and cruise-related consumption retained in the local economy, reduce the cruise industry income leakage, and gradually achieve the import substitution and expanding domestic demand purpose. This requires the introduction of supporting policies and regulations, training cruise management personnel, the construction of cruise supply system and the development of shore sales system, to reduce the cruise ship and cruise fleet rely on to break its monopoly advantage, to achieve self-development and leap. Motherland headquarters economy is the basis of the home port. So, building self-cruise fleet, and gradually forming a scale should be conducted to facilitate the development of home port related supporting services industry.

\subsection{The ideal period}

The ideal stage is that all enterprises cooperate with each other, truly sharing of resources, market sharing, information sharing, brand sharing, benefit sharing and mutual compensation mechanism. Because the cruise industry as a global industry, the cruise fleet itself in short supply, increasing year by year Of the fleet capacity still cannot meet the needs of the market, that is, if and only if there are a number of "Miami" port and cruise fleet oversupply, it is possible to break the cruise company's core monopoly status, cruise service supply chain into ideal stage. Therefore, the prerequisite for entering the ideal stage is to develop self-help cruise, in other words, the need to develop their cruise company. Encourage social and private funds to actively participate in the cruise industry, to guide and support the formation of large enterprises with their own strength of the company, such as shipping companies, port enterprises, tourism integrators, banks, leasing companies The To strengthen the training of cruise professionals, in particular the need to cultivate market research and market statistical analysis professionals in order to better cooperate with the development of the cruise industry, to create a cruise culture and cruise tourism atmosphere, so that cruise close to the general public. 
From the reality, the ideal stage of the cruise service supply chain is to build cruise tourism eco circle. Cruise companies in the ecosystem to improve their quality of service, rich on board leisure and entertainment projects, enhance the brand effect, access to rich quality tourist sources. Port integrators and providers are connecting cruise companies and hinterland cities to continuously transport tourists and goods. As an important link, it is necessary to formulate reasonable fees and improve the compensation mechanism to attract more cruises and promote the effective circulation of the ecosystem. travel integrators and providers have a wealth of tourism resources, dazzling array of goods to attract tourists gathered and sightseeing. Make full use of resource sharing, market sharing and brand effects and other advantages, the development of more distinctive and attractive tourism products, at the same time for different needs, the development of personalized tourism services to enhance the cruise tourism eco-circle of the overall economic benefits. Give full play to the cruise service supply chain their own advantage is to build the basis of tourism ecosystem, but also to achieve the cruise tourism ecosystem and maximize the benefits

\section{Conclusions}

In the growth of the cruise industry mechanism, the market demand plays a guiding role for the growth of the cruise industry. It is because of the requirement of market mainstream, cruise industry in many port city arises at the historic moment. Resources advantages for the growth of the cruise industry supporting role, if not with rich tourism resources and cultural characteristics of port city, the cruise industry development cannot get support, cannot attract cruise for the affiliated; Elements investment impetus to the growth of the cruise industry, the growth of the cruise industry is also the cruise elements of investment, the accumulation of these elements including new build ship, the ship upgrading of leisure entertainment, docking port hardware facilities, shore tourism project investment, good language ability of high quality employees, etc., so the elements both inadequate and excessive investment will be harmful to the cruise industry; The top-level design of function to support the growth of the cruise industry, no matter what stage in the cruise industry development, form a complete set of policy options will have a significant impact on it.

Endogenous mechanism consists of competition and cooperation mechanism. Industry competition and cooperation promote the growth of the industry. Only competition without cooperation or only cooperation without competition industry will not be developed.

The infancy stage of the cruise industry is the market demand and the advantages of port resources. That is, cruise service providers into the professional, training and enhance the competitiveness of the stage. The typical port of the rising stage is the port of Singapore, this stage should focus on the development of downstream industries, improve the economic interests of service providers, focusing on the construction of cruise ship for the logistics centre, driven cruise ship for the development of the market and the cruise industry functions. The typical port of the mature stage is the port of Miami, the home port economic efficiency is the characteristics of this stage, this stage should focus on the development of self-owned 
cruise. The ideal stage cannot be achieved at present, the establishment of cruise tourism eco-circle is the best means of this stage, relying on the advantages of resources, build cruise tourism eco-circle is to play cruise tourism economic benefits and cruise industry to upgrade an effective way.

\section{Acknowledgment}

National Natural Science Foundation of China (71272219, The network attribute of logistics service supply chain and its mechanism to core enterprise growth)

\section{References}

Peter Wild, \& John Dearing. (2000). Development of and prospects for cruising in europe. Maritime Policy \& Management, 27(4), 315-333.

Ying, W., Kyungae, J., Gitae, Y., \& Chienchang, C. (2014). Selecting a cruise port of call location using the fuzzy-ahp method: a case study in east Asia. Tourism Management, 42(42), 262-270.

Iwata H, Matsuda K. (2003). Haptic Walkthrough Simulator: Its Design and Application to Studies on Cognitive Map. The 2nd International Conference on Artificial Reality and Tele-existence, ICAT, PP: 185-192.

Adam Smith. (2007) An Inquiry into the Nature and Causes of the Wealth of Nations. New World Press.

Marshell A. (1920) Principles of Economics. An Introductory Volume. London: Macmillan.

Porter, M. E. (1998) Competitive strategy: techniques for analyzing industries and competitors. Social Science Electronic Publishing (2), 86-87.

Jiying X. (2005). The dynamic mechanism of industrial growth and industry growth model. Academic Forum (7), 49-53.

Guoqing L. (2002). The system dynamic mechanism of industrial evolution and the causes of industrial decline. Hanjiang Forum (4), 15-18.

Xinyu C. (2008). System dynamics analysis of industry growth. Journal of Taiyuan University of Technology (SOCIAL SCIENCE EDITION), 26(3), 27-29.

Jiying X. (2007). Industry growth and its phase characteristics -- Based on the analysis of "S" curve. Academic Forum (5), 83-87. 